\title{
Interacción Simbólica en un Acto de Subjetividad de Género
}

\author{
Ruby L. Espejo \\ Universidad Pedagógica y Tecnológica de Colombia, Facultad de Estudios a Distancia, Grupos de \\ investigación (GIEPEG) y (SIEK) Estudiante Doctorado en Ciencias de la Educación Rudecolombia, CADE- \\ UPTC- Sede central Tunja-Boyacá, Avenida Central del Norte 39-115. Tunja-Boyacá-Colombia, (e-mail: \\ ruby.espejo@uptc.edu.co)
}

Recibido Ene. 8, 2015; Aceptado Mar. 13, 2015; Versión final May. 18, 2015, Publicado Oct. 2015

\begin{abstract}
Resumen
Se analiza la interacción simbólica del acto subjetivo de género desde la experiencia de una formadora de la Escuela de Ciencias Humanísticas y Educación. Desde el enfoque dramatúrgico, y mediante el método fenomenológico-hermenéutico, se examina y cuestiona el sentido y tacto pedagógicos, en situaciones de inequidad de género con posibilidades de intervención en el ámbito universitario. La recolección de la información se deriva de la entrevista en profundidad, analizada a través de tres fases: situación, escenario y agente-audiencia. Las fases, se reflexionan, respectivamente, con tres temas de fondo: género, marcos de la experiencia y fenomenología de la percepción. Se traducen siete situaciones, veinticuatro formas y siete textos. Se concluye sobre la necesidad de analizar la interacción simbólica del acto subjetivo de género, reconociendo vacíos y tensiones, para cuestionarlos desde los contextos educativos universitarios, en procura de equidad de género.
\end{abstract}

Palabras clave: subjetividad de género, interacción simbólica, enfoque dramatúrgico, educación universitaria

\section{Symbolic Interaction in a Genre Subjectivity Act}

\begin{abstract}
The symbolic interaction in a genre subjective act is analyzed from the experience of an educator of the School of Humanities and Education. From the dramaturgical focus, and through the phenomenologicalhermeneutic method, the pedagogical sense is examined and questioned in genre inequality situations with possibilities of intervention in the university environment. The data collection comes from a deep interview, analyzed in three phases: situation, scenario, and agent-audience. Reflection takes place through the three phases with three topics respectively: genre, experience frames, and perception phenomenology. Seven situations, twenty four shapes and seven texts are translated. Conclusions are drawn about the need of analyzing the symbolic interaction of the genre subjective act, recognizing gaps and tensions, to question them from the university educational contexts in favor of genre equity.
\end{abstract}

Keywords: genre subjectivity, symbolic interaction, dramaturgical focus, university education 


\section{INTRODUCCIÓN}

Es evidente que son múltiples y complejas las situaciones de inequidad de género que suelen estar presentes en todos los ámbitos de la vida cotidiana. En mayor o menor grado, de manera expresa 0 implícita, estas situaciones inciden en los procesos de construcción de subjetividades. Este hecho resulta particularmente significativo cuando se trata de actores educativos que desarrollan procesos de enseñanzaaprendizaje en ámbitos formativos como los universitarios, toda vez que afectan su quehacer pedagógico. Se tomen decisiones o posturas de rechazo, indiferencia o aceptación frente a actos de injusticia, discriminación o abuso, siempre estos actos producen tensiones, vacíos y, sobre todo, posibilidades de cuestionamiento. Frente a esta realidad, cobra fuerza la necesidad de leer y comprender la cotidianidad de las experiencias desde los discursos, actitudes y actuaciones de quienes forman (Freire, 2005; Gadamer, 2007; Saúl et al, 2009) a nivel universitario. La razón de esta exigencia radica en que este ejercicio puede ayudar a poner en evidencia y a re-significar, en escenarios educativos, las tensiones, vacíos y posibilidades que se dinamizan allí entre igualdad-desigualdad (Thezá, 2003).

En este sentido, revisar la equidad de género, que según especialistas como Alvariñas y Fernández (2011) en el eje de aprendizaje, resulta esencial, dado el protagonismo que esta categoría social despliega en los procesos de desarrollo formativo, como acto que da la oportunidad de crecer personalmente (Lobato y Madinabeitia, 2011). En otras palabras, es en este acto en donde la subjetividad se construye y fortalece, puesto que en el proceso de construcción de conocimiento y de expresión discursiva en situaciones reales (Mancilla, 2006; Martínez, 2013) se despliega la adquisición de competencias y de responsabilidad educativa. Sin embargo, la poca o nula consciencia o interiorización de estos actos de autoformación y posicionamiento como sujetos activos y participativos, revela la falta de consciencia y por ende de protagonismo de los sujetos, un hecho que en el tema tratado se constituye, en últimas, en una de las principales debilidades de los procesos pedagógicos. De ahí que sea fundamental trabajar en el aprendizaje para procesar y entender la información recibida desde sus diferentes posibilidades en la cotidianidad de los procesos de enseñanza y aprendizaje, con el fin de evitar la reiteración o réplica de actos y discursos de inequidad de género.

En esta tarea, como lo plantean Póo y Vizcarra (2011), procesar y comprender la cotidianidad del acto educativo es traducir las experiencias directas desde las actividades mismas, colocando en perspectiva de análisis e interpretación las múltiples posibilidades de intercambio de ideas y opiniones en el quehacer pedagógico, pues es este proceso el que permite la apropiación de los actos, discursos, y la misma postura crítica como educadores/as y como sujetos. Este acto, en otras palabras, se va constituyendo en una forma de generar conocimiento desde la dinámica y el cuestionamiento producidos en la actividad misma. En este sentido, Zuñiga (2006) aporta a esta perspectiva de análisis y de trabajo pedagógico cuando concluye que cualquier esfuerzo por visibilizar la relación universalidad-particularidad necesita como punto de partida el sujeto individual (Scott, 2008). Esta mirada contempla la posibilidad de que el sujeto, que por influencia de otras subjetividades más fuertes y dominantes, puede convertirse en un sujeto atemperado o débil (López, 2013), pero, puede tener una posibilidad significativa, que esta misma opresión puede llegar a exaltarlo y llevarlo a tomar consciencia de las razones de su estado o su ser o estar en el mundo. Esta reacción puede generar autonomía, valoración y justificación del ser humano para trabajar en la erradicación de situaciones de inequidad. En cualquier caso, en mayor o menor grado, no puede desconocerse el atributo formativo humano (Gadamer, 2007) que posee la sociabilidad por el hecho de desarrollar en sí misma la dignidad y equidad dentro de lo diverso. Por ello, en ese nudo de construcción, lo social hace presencia a través de los vacíos, tensiones y el reclamo de posibilidades (Saúl et al, 2009; Jiménez et al., 2013) en una sociabilidad que configura la dimensión situada (Goffman, 2006), con su carga de posibilidades de cambios. Pero, plantear su desarrollo es contemplar otros mundos, incluso, aquellos por construirse dentro de procesos históricos (Merleau-Ponty, 1993). Por esto, podemos considerar que en la construcción se encuentra el reclamo por esa agencia (Butler, 2007), por ser la que constituye la defensa, autonomía y dignidad del ser humano frente a dominaciones u opresiones exógenas.

De acuerdo con lo expuesto, el tema abordado en este artículo se pone en perspectiva en un escenario universitario específico, que trasciende a otros ámbitos de la Educación Superior, a partir de esta pregunta problematizada: ¿Cómo se percibe cotidianamente el acto de subjetividad de género en quienes conducen procesos formativos en la Escuela de Ciencias Humanísticas y de Educación de la Universidad Pedagógica y Tecnológica de Colombia y cómo se refleja ello en su sentir y tacto pedagógico? Su desarrollo se traduce desde lo cualitativo, dramatúrgico y fenomenológico-hermenéutico.

\section{METODOLOGÍA}

De acuerdo con lo planteado, se hizo el análisis y comprensión del acto de subjetividad de género en una educadora universitaria desde el componente social e individual que el acto pedagógico encierra. En ello, el 
el escenario educativo, donde se desenvuelven los actores, brindó actuaciones, discursos, gestos, actitudes, entre otras expresiones subjetivas, que desde lo cualitativo fueron sustanciales. Aquí tuvo especial importancia el enfoque dramatúrgico que, mediante los marcos de la experiencia de Goffman (2006), favoreció el análisis del interaccionismo social simbólico como actuación. Se puso así en escena el cuerpo dentro del proceso biográfico que transita entre la búsqueda, expresión y afirmación de una identidad subjetivada, en tránsito permanente, que desafía distintas maneras de ser en el mundo. Esto permitió distender el significado corporal del cuerpo que, a medida que se expresaba y actuaba, iba proporcionando claves de lo conflictivo de la intersubjetividad. Es decir, explorar no solo lo evidente sino lo latente.

El examen se centró en los quiebres, provocados por acontecimientos significativos que pueden o no producir cambios, y que se presentan en escenarios nuevos que, a pesar de provocar insatisfacción en quienes los viven, e incluso, en ciertos momentos los transgreden, continúan siendo latentes puesto que no se comprenden y asimilan a profundidad y, muchas veces, se quedan en el ámbito de lo privado. Mostrar aquí que se puede hacer pública la insatisfacción de estas situaciones estuvo en consonancia con darle forma dentro de un lenguaje, "que pueda dar voz y cuerpo a lo hasta ahora reprimido y negado" (Hurtado, 2006), partiendo, precisamente, de quien padece la represión (Díaz, 2004; Díaz, 2014).

Así, en el desarrollo de esta metodología se abordaron dos elementos claves: uno, la experiencia vivencial, y dos, la profundización en el proceso de la experiencia. Este último, se aborda desde tres fases yuxtapuestas en tres categorías de análisis interrelacionadas: (1). La situación, (2). El escenario o área de acción y (3). El agente, entendido en un doble papel, en ocasiones como agente y en otras como audiencia. En este sentido, resulta pertinente el método fenomenológico-hermenéutico (Van Manen, 2003; Carabajo, 2008) pues este tiene como objeto de estudio lo empírico, que es contingente, variable y complejo, por lo cual no sigue procedimientos investigativos convencionales ni de dominio universal. Este método, como lo propone Van Manen, es más bien un camino de estrategias, técnicas o tácticas que se superponen y asumen según las circunstancias.

Dado que este método no intenta resolver problemas, sino generar, desde el simbolismo de la experiencia vivencial (signos, significaciones, señales), una serie de cuestionamientos referidos a la subjetividad e intersubjetividad, surgieron en este sentido los siguientes interrogantes: ¿Cómo se vive la experiencia? ¿Cómo la entiende quien educa? ¿Cuál es la naturaleza de ese acto de subjetividad de género, esencial, experimentado y vivenciado? ¿Se puede o no percibir relación con lo educativo?

La pertinencia del método desarrollado fue evidente: dado el interés de la investigadora en el estudio del significado esencial del acto de subjetividad de género desde su papel formativo, le permitió cuestionarse desde lo educativo y lo pedagógico del fenómeno. Además, por ser parte del ejercicio investigativo, generó confrontación y comprensión de esa relación entre fenomenología-hermenéutica y su vinculación con la práctica. Estos presupuestos dieron pues validez al método, por ser de naturaleza tanto empírica como reflexiva, y además, porque permitió encontrar en su desarrollo la manera de actuar, transversalmente, dos elementos metodológicos: la reducción y lo vocativo.

Desde la reducción eidética (Van Manen, 2003) se determinaron los temas de fondo (género, marcos de la experiencia y fenomenología de la percepción) para profundizar en las tres fases o categorías, y poder interaccionar así: (1) en la definición de la situación, se optó por el tema de género, constituyendo el feminismo una connotación emancipadora tomada como base del análisis, contrapuesta al machismo, esto desde la teoría de género de Joan Scott (2008); (2) en la elección del escenario, se definió la acción como instancia de interacción de la situación, aquí fue pertinente el tema de los marcos de la experiencia de Erving Goffman (2006); y (3) el agente, en ocasiones audiente, justamente quien necesita se le revise la consciencia del acto, constituyéndose en este sentido el tema de la fenomenología de la percepción de Merlau-Ponty (1993) esa posibilidad de análisis.

En relación con lo vocativo (Van Manen, 2003), se trabajaron estrategias de escritura. De esta manera se abordó la experiencia desde un proceso inductivo con la entrevista en profundidad (Alonso, 1999). Para ello se desplegó la perspectiva narrativa-biográfica (Mckernan, 1999; Mena, 2014), sirviendo como fondo de quien investiga los tres temas puestos en relación: el género, para preguntar experiencias de situaciones de inequidad de género; los marcos de la experiencia, para hacer una lectura del marco de referencia del acto de subjetividad de género en quienes escénicamente convergen intersubjetivamente, dentro de la situación, y la fenomenología de la percepción para revisar la consciencia del acto en tanto agente o audiencia. Esto permite la selección de situaciones que revelan el fenómeno estudiado, para ser reescritas en texto fenomenológico en tanto solicitud pedagógica. 
Para seleccionar a la persona entrevistada, se elaboró una muestra estructural no estadística, sustentada en Ibáñez (1990), quien sostiene que para la composición del grupo y la selección del número de sujetos estudiados, tener presente un número mayor de los mismos no supone más información, sino mayor redundancia. Es decir, no es relevante la cantidad de informantes, lo fundamental es la expresión de la experiencia personal de la situación de género y alguien dispuesto a narrarla. Se hace por tanto una revisión de carácter individual, una subjetividad desplegada en actos consigo mismo y con los otros, sin descartar la posibilidad, a posteriori, de ser comparada con otras.

Los conceptos, fases, temas y categorías imbricados en el desarrollo de la metodología se sintetizan en la Figura 1. Enfoque dramatúrgico desde el método fenomenológico-hermenéutico, donde se puede apreciar la interrelación entre el enfoque, el método, las fases, las categorías, la entrevista, los temas de fondo, la reducción eidética, lo vocativo, las 24 formas emergentes: siete de género, diez de los marcos de la experiencia y siete de fenomenología de la percepción. La entrevista a la formadora será mencionada como Entrevistada en lo que sigue.

\begin{tabular}{|c|c|c|c|c|c|c|}
\hline \multicolumn{7}{|c|}{ Enfoque dramatúrgico, Goffman (2006) } \\
\hline \multicolumn{7}{|c|}{ Ejemplo de análisis de interacción simbólica } \\
\hline $\begin{array}{c}\text { Uno: } \\
\text { La } \\
\text { experiencia }\end{array}$ & \multirow{4}{*}{ 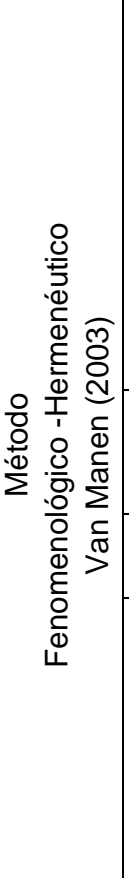 } & $\begin{array}{c}\text { Entrevista en } \\
\text { profundidad } \\
\text { (Alonso, 1999) } \\
\\
\text { Recoge } \\
\text { experiencia } \\
\text { Vivida } \\
\text { (Entrevistada) } \\
\\
\text { (empírico) }\end{array}$ & $\begin{array}{l}\text { Situaciones } \\
\text { Privilegia - acto } \\
\text { de subjetividad } \\
\text { de genero } \\
\text { (empírico) }\end{array}$ & 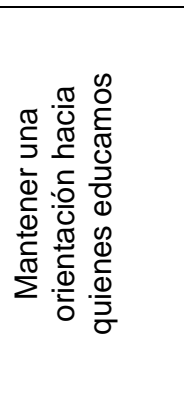 & 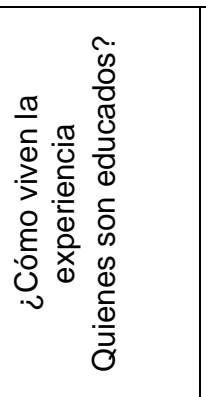 & 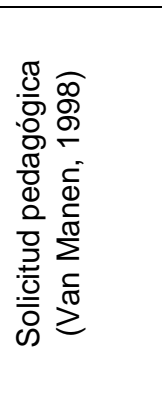 \\
\hline \multirow{3}{*}{$\begin{array}{l}\text { Profundizar } \\
\text { en (3) fases }\end{array}$} & & Fenomenológico & $\begin{array}{c}\text { Dimensión } \\
\text { vocativa }\end{array}$ & $\begin{array}{l}\text { escribe } \\
\text { experiencia } \\
\text { vivida }\end{array}$ & \multirow{3}{*}{ 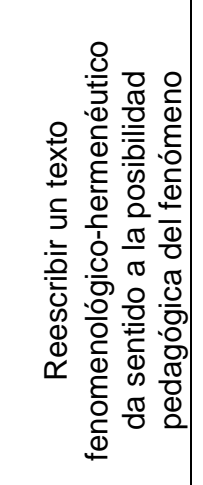 } & \multirow{3}{*}{ 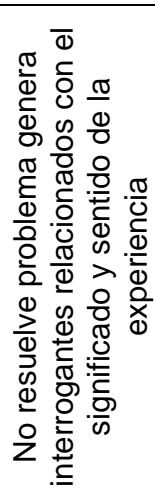 } \\
\hline & & Hermenéutico & $\begin{array}{l}\text { Reducción } \\
\text { eidética }\end{array}$ & \multirow[b]{2}{*}{$\begin{array}{l}\text { hacer } \\
\text { reflexión } \\
\text { de fondo }\end{array}$} & & \\
\hline & & $\begin{array}{l}\text { Temas } \\
\text { de } \\
\text { fondo } \\
\text { (g) (me) (fp) }\end{array}$ & $\begin{array}{l}\text { Hermenéutica } \\
\text { Reflexión de } \\
\text { fondo } \\
\text { (24 formas) }\end{array}$ & & & \\
\hline (1) Situación & \multirow{3}{*}{ 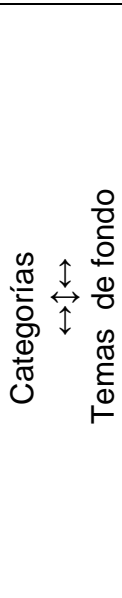 } & \multicolumn{2}{|c|}{$\begin{array}{c}\text { Género (g) (Scott, 2008): (7) formas } \\
\text { (ADCRBDS), (ASFPRSP), (CDCSF) } \\
\text { (SC) (CN), (IyO) (lyS). }\end{array}$} & \multirow{3}{*}{$\begin{array}{l}\frac{0}{2} \\
\frac{1}{0} \\
0 \\
0 \\
0 \\
. \frac{\pi}{0} \\
\frac{0}{0} \\
\frac{1}{0} \\
\frac{0}{E} \\
0 \\
0\end{array}$} & \multirow{3}{*}{ 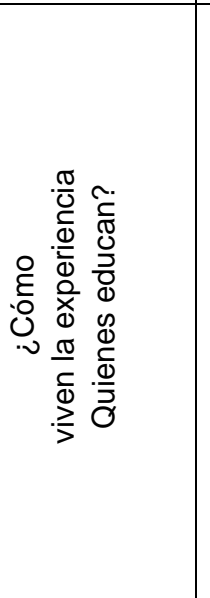 } & \multirow{3}{*}{ 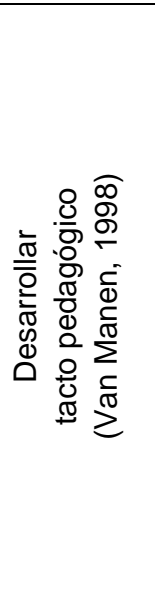 } \\
\hline $\begin{array}{l}\text { (2) Área de } \\
\text { acción } \\
\text { o } \\
\text { escenario }\end{array}$ & & \multirow{2}{*}{\multicolumn{2}{|c|}{$\begin{array}{r}\text { Marcos de } \\
\text { (Goffman, } \\
\text { (MRP), (MRP } \\
\text { tc), (MRPs- } \\
\text { (MRP } \\
\text { (MRF } \\
\text { (MRP } \\
\text { (MRF }\end{array}$}} & & & \\
\hline $\begin{array}{l}\text { (3) Agente } \\
\text { Audiencia }\end{array}$ & & & & & & \\
\hline
\end{tabular}

Figura 1. Enfoque dramatúrgico desde el método fenomenológico-hermenéutico

\section{RESULTADOS}

Los resultados presentados son un primer avance del proceso investigativo. Se desarrollan así: en primer lugar, se presentan los temas de fondo (reducción eidética); en segundo lugar, se describen algunas 
situaciones extraídas de la entrevista a la formadora (dimensión vocativa); en tercer lugar, se hace una mayor reducción eidética por la relación encontrada entre los temas de fondo y las situaciones extraídas (ver figura 1. Enfoque dramatúrgico desde el método fenomenológico-hermenéutico), en total se reducen a 24 formas sobre las cuales se hace la reflexión; en cuarto lugar, se da juego a lo vocativo-eidético o empírico-hermenéutico, desde la reescritura del texto fenomenológico-hermenéutico; finalmente, se hace la discusión de resultados.

\section{Temas de fondo (reducción eidética)}

Se presentan y analizan tres temas: género $(\mathrm{g})$, los marcos de la experiencia (me) y fenomenología de la percepción (fp)

\section{Género $(\mathrm{g})$}

Para hallar el sentido de lo que representa una situación de género, el sujeto se asume como individuo que interactúa dentro de organizaciones e instituciones sociales en las que se desenvuelve cotidianamente, esto con el fin de indagar y conocer de qué naturaleza son sus acciones e interacciones. Se asume así porque acción (subjetividad) e interacción (intersubjetividad) son dos actos presentes en toda relación social que brinda elementos discursivos y simbólicos que permiten comprender el funcionamiento del género como categoría social. Por eso mismo, es preciso revisar la manera en la que el poder social (Foucault, 1989) se unifica y centraliza, moviéndose dentro de relaciones desiguales, las cuales también se constituyen, discursivamente, en campos sociales de fuerza. En este sentido, el feminismo desde una percepción hacia la emancipación hace parte del análisis, tal como lo plantea Scott (2008).

Scott (2008) presenta la concepción de género desde dos proposiciones estrechamente relacionadas: la primera, como elemento constitutivo de las relaciones sociales basadas en las diferencias personales percibidas entre los sexos; la segunda, como forma primaria constituyente de las relaciones simbólicas de poder social. De estas dos proposiciones resultan cuatro elementos integrados en ellas: (1) los símbolos construidos culturalmente, que con frecuencia son representaciones contradictorias, el caso de considerar la actividad doméstica como trabajo, pero no remunerado, por asumirse como inherente a la condición femenina subestimada; (2) los conceptos normativos resultantes de la interpretación de los símbolos construidos culturalmente, es decir, lo interpretado contradictoriamente, que se convierte en norma; (3) la institucionalización en las organizaciones familiares, económicas, políticas, educativas de actos de subjetividad de género presentándose como si obedecieran a un consenso y no a la dinámica conflictiva de intersubjetividad, esto es, la norma que se impone inicialmente en el hogar, trasciende y se posiciona en otras esferas de la vida social y, 4) la identidad y subjetividad como elemento para plantear la reproducción del género a partir de la comprensión de la transformación de la sexualidad biológica de los individuos a medida que son aculturados, en-generados. Se entiende este elemento incluido dentro de un proceso que pone en relación los discursos sociales constitutivos (lo personal, los niños juegan con carros, las niñas con muñecas) y los instituyentes (en su condición de niñas, les "toca" asumir la crianza de sus hijos/as, por ejemplo) desde donde se configuran discursos propios ligados a determinado reclamo colectivo de subjetividad en su dimensión histórica-biográfica, es decir, la historia personal configura su subjetividad de manera progresiva en la cotidianidad del mundo de la vida.

\section{Los marcos de la experiencia (me)}

Constituyen la manera subjetiva de organizar la percepción. Este referente perceptivo se intersubjetiva dentro de las relaciones sociales; por eso mismo, las situaciones dinamizadas dentro de la interacción simbólica exigen actuar de manera constante, constituyéndose este referente en el marco de referencia primario (MRP), referente utilizado por quien actúa para dar sentido a cualquier aspecto sin sentido en una escena. Los (MRP) se clasifican en dos grandes tipos: Los Naturales (MRPn), entendidos sin dirección ni guía de un agente o agencia, y los Sociales (MRPs), catalogados como aquellos que proporcionan una base de entendimiento de los acontecimientos. En estos últimos se incorpora la voluntad, objetivo y esfuerzo de control de una inteligencia, agencia viva que erige al ser humano como su más importante objetivo de conocimiento y comprensión. "Esta agencia que lo es todo, menos implacable, puede llegar a ser adulada, engatusada, insultada y amenazada desde un proceso central dinamizado por haceres guiados" (Goffman, 2006).

De todas formas, es en el esquema interpretativo donde cabe la suscripción a un nivel de gradación superior que permite moverse dentro de los marcos de referencia primarios naturales y sociales. Desde esta intersección se puede trabajar lo llamado por Goffman (2006) claves. Así, quienes perciben en sus interpretaciones las claves, pueden partir de ellas y generar posibilidades de agentes socializadores, porque es en interpretaciones como estas donde cabe la transposición de claves. Por tratarse de un proceso 
dinámico, siempre se debe tener en cuenta que el modelo es el punto de partida de quien coloca en perspectiva su acto y que desde allí lo agencia, es decir, interacciona entre dos posibilidades: modelos para transponer claves para entender la esencia de donde parte la percepción de hombre o mujer y tomar una posición crítica; o en su defecto, sigue "modelos de" hombre o mujer, utilizados para fomentar fabricaciones, esto es, por ejemplo, estereotipos de mujer u hombre.

Es preciso señalar aquí, por una parte, que los Marcos de referencia naturales están subdivididos en 1) aquellos atribuidos a fenómenos naturales, por ejemplo, nacer y 2) los entendidos como debidos de principio a fin, configurados dentro de los sucesos y acontecimientos sin dirección ni guía, por ejemplo, cuando se asume que como mujer u hombre "toca" actuar reproduciendo "etiquetas" de uno u otro. Por otra parte, los marcos de referencia sociales se subdividen en 1) Manipulación patente del mundo natural, en la socialidad lo natural se yuxtapone con lo social 2) Mundos especiales en donde puede participar el actor, son las transposiciones claves como posibilidad formativa y 3) Manipulación del mundo físico, adoptando la identidad de un procedimiento instrumental, por ejemplo, la mujer asume roles que la convierten en un objeto manipulable.

\section{Fenomenología de la percepción (fp)}

El ser humano no es perfecto, y más que buscar perfección su finalidad es que su ser tenga un sentido que se transparenta en la intersección de sus experiencias con las de otras u otros sujetos sociales. Se entiende aquí que subjetividad e intersubjetividad son inseparables, esto es, son dos construcciones del sujeto individual y social que configuran una unidad a través de la transposición o reasunción (Goffman, 2006) de sus experiencias pasadas en sus experiencias nuevas. De este modo, "nosotros", en tanto cuerpo vivencial (Merlau-Ponty, 1993), asistimos a cada instante a ese prodigio de conexión de experiencias. Por esta razón, nadie mejor que "nosotros" sabe cómo se efectúa esa conexión, por ser, "nosotros", ese nudo de relaciones. Así mundo y razón para cada sujeto pueden ser diferentes si se consciencia la subjetividad. Esto no representa ningún problema, pues incluso, estas concepciones pueden ser misteriosas, pero es ese misterio y complejidad lo que las enriquece al no tener etiquetas, sino que tiene la posibilidad de distintas maneras de ser en el mundo que pueden apoyar formas de ser distintas, es decir, que esa diferencia, o misterio, los define. Pero, llegar desde la fenomenología a disipar el misterio con soluciones, en modo alguno sería dejar de lado la fidelidad de meditación infinita por la que aboga, pues el misterio está más acá de las soluciones. Por eso se tiene presente a Merlau-Ponty (1993) quien sostiene que hacer verdadera filosofía es aprender de nuevo a ver el mundo, en donde relatar una historia es una ayuda reveladora, porque puede significar el mundo revisado a tal profundidad como lo puede hacer un tratado de filosofía. Lo fundamental acá es la noción de cuerpo que de objeto (instrumental) pasa a ser signo con significado, cuerpo consciente.

Dentro de las historias, la reflexión (Merlau-Ponty, 1993) se constituye en una posibilidad de tomar consciencia crítica tanto de la subjetividad como de la intersubjetividad en un acto. Es decir, cada uno es responsable de su historia. Y es en las decisiones en las que cada uno empeña su vida, porque reflexionar como decidir son actos violentos verificados al momento de comunicarnos y de rechazar, optar o tranzar en uno u otro sentido. En síntesis, al movernos y presentarnos dentro de un espacio y un tiempo estamos haciendo signo con nuestro cuerpo (Merlau-Ponty, 1993), pues en lo contingente ese movimiento tiene opciones: envolver (ser concreto) o desplegar sus partes (buscar posibilidades de mundos diferentes). Cuando envuelve sus partes, se toma de fondo el movimiento concreto donde los mundos están dados volviéndose el cuerpo objeto de un mundo que no es suyo, o, al desplegar las partes, se toma como fondo el movimiento abstracto donde cabe la concienciación de la subjetividad en la construcción del mundo mismo y otras posibilidades. Si se opta por el despliegue del cuerpo y un fondo de movimiento abstracto, el diálogo constituye esa posibilidad que avivará la llama en ese prodigio de conexión de experiencias (MerlauPonty, 1993). Es en este aparte, donde se hace la aproximación a lo que encierra la interacción simbólica como conjunto de signos corporales, subjetivos e intersubjetivos:

\section{Algunas situaciones}

Se presentan y analizan siete situaciones extraídas de la entrevista en profundidad realizada el 15 de julio de 2014, en Tunja (Entrevistada).

\section{Situación uno (Dimensión vocativa)}

\section{Pregunta $(P)$ ¿Una sucinta descripción de quién es?}

Respuesta (R): Edad: 42 años, tengo tres hermanas; un hermano, tecnólogo en mercadeo agropecuario; [mi papa, es pensionado del magisterio, mamá, no trabaja... gerente de hogar], (SC). Me casé por lo católico, a los 19 años más o menos. Tuve dos hijos, el mayor 23 y el menor 15. $(P)$ ¿Fueron los hijos proyectados? $(R)$ : [Pues si uno dice, cuando yo me case quiero tener dos hijos, sí; el primero sí fue de sorpresa... 
(risas)... Era muy joven, acababa de salir del colegio, entonces mi proyecto de vida era otro], (MRPn). (P) ¿Por qué de sorpresa? [Una falta de conocimiento, porque digo yo por ingenuidad], (MRPs)(2)(mepa) [Más que todo por falta de conocimiento], (MRPs)(2)(mepa). (P) ¿El hermano si fue programado? [Sí porque yo... había estudiado y todo], (MRPs).

\section{Situación dos}

Pregunta. ¿Podría contarme la experiencia como mujer?

[Bueno, mi niñez no fue digamos de... cosas materiales, sí; pero faltaron muchas cosas. No tuve la presencia de mi papá, sí... Es algo fundamental en el desarrollo, la presencia del padre y de la madre] (SC) [pero no creo que me haya hecho mucha falta tampoco, porque mi mamá supo defenderse; entonces no teníamos todo lo material, pero sí teníamos mucho cariño, mucho afecto y disfruté mucho la niñez], (lyS). [Ya en la adolescencia sí me sentí un poco más sola, mi mamá se fue -se agudiza la voz..- con mi papá quedamos casi que solos. -Silencio, lágrimas-... llorar...- mi papa le dijo, fue mi mamá o ella o sus hijos... y ella se fue, quedamos casi que solos, (CDCSF) hay... (i...lágrimas...silencio...si me disculpa...!quedamos casi que solos!)], (MRPs) (2) (mepa). Se fue para Santander [y yo (yo) terminé ya el bachillerato... al año siguiente quedé yo (yo) embarazada, (HSC) -(se agudiza la voz....tristeza). Me tocaba... no pude estudiar mejor dicho...yo tenía otro proyecto de vida que era estudiar una ingeniería... era muy joven, acababa de salir del colegio, entonces mi proyecto de vida era otro, quedé embarazada]. (MRPn). [pensé que iba tener más apoyo de mi mamá, pero no lo logré, entonces tuve mi hijo y tenía 17 años... casi que... me fui a la casa de mis suegros, no porque yo lo quisiera... sino porque no tenía quien me ayudará, quien me colaborará por mi hijo porque era una nueva experiencia y no sabía qué hacer], (CDCSF), [entonces me fui a la casa de mi esposo y ahí me quedé, me quedé hay recibí buena ayuda por parte de mis suegros y ahí mi vida cambio. Pues no era lo que yo quería], (CDCSF), [no quería estar comprometida con nada sino quería como mientras las otras personas estaban disfrutando estudiando, a mí me toco empezar a trabajar desde los 18 años hasta ahora] (MRPn).

\section{Situación tres}

Empezamos al tiempo a estudiar, él empezó a estudiar Economía y yo entré a estudiar Idiomas, a él no le gustó la economía y se retiró. Yo si seguí estudiando... pero eso fue terrible porque a él no le gustó que yo siguiera] (CDCSF), [porque el sentía que yo iba más adelante que él y entonces... para estudiar eso fue terrible, yo le soy sincera... Eso fue terrible] (CDCSF) $(P)$. ¿Por qué? [Él me formaba unas peleas terribles, yo a veces entraba hasta llorando a clase. Él me trataba muy mal (CDCSF), decía que él estaba sacrificándose mientras que yo estaba superándome, pero yo le decía si ambos trabajamos, si su trabajo era fuerte más que el mío, a él le tocó muy duro también, a él le tocaba... El papá era contratista y a él le tocó empezar desde abajo, pues sí, yo sabía, yo lo entendía, le decía: a usted le tocó igual que yo, estudiar y trabajar; sino que usted no quiso estudiar más y eso que yo le ayudaba y, yo, sigo en la lucha porque yo quiero salir adelante] (CDCSF).

\section{Situación cuatro}

Pregunta. ¿Ha percibido en esa experiencia de mujer, inequidad de género? (R),

[Sí creo y todavía lo creo, es difícil de aceptar pero todavía lo creo (CDCSF), porque ellos creen que solo lo que ellos hacen es duro sí, y lo que uno hace pues si esto, pero no es lo mismo (ADCRBDS). Ahí veo una inequidad, Por ejemplo, mi esposo dice a mí me toca duro]. [Todavía me dice me toca ir a una obra, subir pisos, mirar que la gente trabaje, mirar qué están haciendo, que esto que lo otro, cuidado con esto, con lo otro; todas las actividades, que el sol, el agua y usted simplemente llega a una oficina a sentarse] (ADCRBDS). [Entonces le digo que eso no es así, porque mi trabajo pueda que no sea al aire libre como le toca a usted pero me tocan muchas cosas y aparte de eso me toca llegar a una casa y responder por otras actividades y estar todo el día con los hijos, todo. Yo creo que es más trabajo el que uno hace, pero ellos no lo ven así, ellos llegan a la casa se sientan, de vez en cuando que le colaboran a uno pero de resto] (SC) $(\mathrm{CN})$.

\section{Situación cinco}

Pregunta. ¿Podría contarme las actividades desarrolladas desde la hora que se levanta hasta cuando se acuesta para descansar? $(\mathrm{R})$,

[mi día empieza desde las cinco: hago el desayuno, levanto a mi hijo para que se aliste para el Colegio. Mientras hago el desayuno, voy haciendo el almuerzo, ya mi hijo se va... yo tengo que dejar la casa... He barrido, arreglado cocina, lavo, arreglo, por eso a veces me coge la tarde. Mejor dicho, a las 8.00 ya he hecho desayuno y almuerzo, y salgo a las 8.00 de la mañana. A medio día yo llego y termino de hacer el almuerzo, ¡medio almuerzo! ¡Ni tengo tiempo de sentarme a descansar cinco minutos!] (MRPs)(3)(mmfai), [porque tengo que lavar loza, dejo todo arreglado y debo dejar listo el almuerzo de mi hijo... para que 
apenas caliente. Llega hasta las dos de la tarde, no nos alcanzamos a ver. Trabajo hasta las 6.00 de la tarde, cuando llego a la casa ya han hecho onces tomo, cuando no las hago, preparo la comida, miro si hay que arreglar algo, si hay que arreglar algo lo hago, dejo todo arreglado para el día siguiente y por ahí a las 9.00 de la noche me pongo a leer y revisar trabajos de la universidad, así... lo que tenga pendiente hasta las once, once y media de la noche] (MRPs-m-f) (HSC) (CS) (CN) (lyO) (CE).

¿Qué actividades desarrolla su esposo desde que se levanta hasta acostarse? (R), [Ahorita, pues no tiene trabajo, está hace un año sin trabajo. Es diferente cuando está con trabajo a cuando está sin trabajo. Ahorita que está sin trabajo, él se levanta a las 6.00 de la mañana, se arregla y tiene la costumbre de acompañar a mi hijo hasta el parque Pinzón, como por salir a caminar y se devuelve... Ya el desayuna, yo le sirvo el desayuno, desayuna] (CS), y [luego, ya a las 8.00 de la mañana, se va con el hermano. Él dice que está pasando propuestas, sale al centro; dice que a hablar con los ingenieros a ver si consigue trabajo aquí. Dura a veces toda la mañana, llega a medio día. Ahorita que estoy en la casa no me ayuda a hacer nada de almuerzo. Él se sienta, se pone a mirar televisión, espera que yo le sirva. Yo recojo, lavo y arreglo, por la tarde se acuesta un rato a dormir, luego se levanta y se va otra vez para el centro con el hermano, llegan por la tarde a tomar onces y a mirar televisión, y luego, la comida... Se acuesta a dormir, por ahí a veces se queda un rato en el computador.] (MRPs-m-f)-(HSC) (CS) (CN) (lyO).

¿Ha sugerido su colaboración en las actividades de la casa? (R). [Hasta este año, pues yo siempre tuve un tiempo que todo me tocaba sola, después contraté una china que fue la de ese problema... Me colaboraba haciendo el oficio de la casa, porque cuando estuve enferma... Ahorita estoy en las mismas, entonces me tocó contratar a esa señora y entonces con lo del robo me tocó prescindir de sus servicios. A mí me toca duro] (MRPs)(3)(mmfai), [al comienzo él llegaba y yo estaba trabajando y él tiene de 12.00 a 1.15 de almuerzo, y a la 1.30, empieza a trabajar, entonces yo llegaba a la casa y el pretendía que cuando yo llegará le tuviera servido todo] (MRPs)(3)(mmfai), [entonces eran unas peleas porque no alcanzaba a comer](CDCSF).

\section{Situación seis}

Pregunta. Menciono haber contratado alguien. Al pagar, ¿cómo distribuyen ese pago?

$(\mathrm{R})$. [Al pagar la empleada, pues yo] (CDCSF), $(P)$ ¿No hay retribución económica a pesar de que ambos trabajan? [No yo, ¿por qué yo?, él me dice ese es su problema, esa persona le está ayudando porque es su responsabilidad sí] (CS) (CN). [Entonces yo, por no pelear, no digo nada] (HSC) (CE), [yo asumo todo] (MRPs)(3)(mmfai), [el si me ayuda por mitad, ejemplo, lo que es el mercado todo eso] (CDCSF).

\section{Situación siete}

Pregunta. ¿En el ejercicio de su profesión ha experimentado situaciones de inequidad?

(R). [Yo me he sentido bien] (ASNR)... [Por ejemplo, si me dio duro cuando empecé a trabajar, entonces la gente se aprovecha mucho de uno, incluso cuando yo estaba trabajando por contrato cuando yo era joven trabaje en la Alcaldía OPS. Entonces una vez hubo cambio (era por política) de alcalde, entonces la directora me dijo] (lyO) [tiene que hablar entonces con el Secretario de Educación] (lyO) y [va y habla con él para que por favor le colabore, va y le dice oiga que usted ha trabajado, eso fue en el año 93, cuando salió la Ley 60, y yo fui y hablé con el viejo] (ASFPRSP) [este y me propuso una cosa] (HSC) (MRPs)(1)(mpmn) [que usted ni se imagina. Entonces lo que yo hice, le menté hasta la abuela y entonces me quedé sin trabajo, pero yo dije preferible sin trabajo. No me gustó, me sentí tan juyyyy! Muchas compañeras salieron hasta nombradas pero yo no... [risas...]] (lyO) (CS) (lyS) (MRPs-m-f) (CD) (FMA). [Entonces fue cuando fui a La Presentación y allí todo el mundo decía que eso era con palanca y yo fui] (MRPs)(2)(mepa) [como si nada y le dije a la monja la única referencia que tengo es el de arriba] (MRP), [porque de resto no tengo a nadie] (MRPn)(1)(fn). [A ella le dio risa, y dijo para qué más. Yo entré a trabajar allí, lo mismo en la Universidad, yo entre por concurso, no entré por palanca ni nada de eso... Y así no me he sentido vulnerada ni porque ser mujer ni porque no tenga influencia, no he sentido nada] (ASNR).

[Por ejemplo en La Presentación si vi cuando yo trabajé... más apoyo a los hombres $(P)$ ¿Por qué? En el trato, pese a que conmigo bien, pero se veía cómo a los hombres los consentían. Si tenían que pedirle permiso se los daban sin decir nada, pero uno llegaba a pedir permiso ahí si grave; pero con ellos sí eran condescendientes] (CS) (CN). [Por ejemplo, en La Presentación una vez hubo un problema con unos profesores y profesoras que se metieron, y unas eran casadas, ¿y qué hicieron? Sacaron a todas las mujeres, que por vagabundas, y las echaron del Colegio. A los hombres si los dejaron seguir trabajando] (ADCRBDS), [entonces uno si sentía esa falta de equidad. A los hombres no les dijeron nada y a las mujeres sí las echaron...] (lyO) (lyS). 
(P) ¿Ha contemplado trabajar por la equidad de género dentro de la asignatura o asignaturas que orienta? (R), [claro, uno puede proyectar, no estoy de acuerdo, doy aportes generales, dando a entender lo que quiero] (MRPs)(2)(mepa).

$(P)$ ¿En su experiencia docente se han presentado situaciones de género?

$(\mathrm{R}),[i$ Claro, varias!... En una tutoría hay un muchacho que tiene sus tendencias diferentes a las de hombre, mujer, usualmente un término medio. Entonces en eso soy muy respetuosa. Pasó que ese muchacho siempre que pasaba a exponer ese muchacho, había un grupo que se burlaba de él, lo criticaban y el muchacho perdió mucho la confianza, porque dejó de participar, porque los otros se burlaban. Entonces yo hice un comentario] (HSC) [refiriéndome a una situación que había pasado alguna vez, refiriéndome a que uno no tiene el derecho ni la facultad de degradar a nadie. Entonces yo les di a entender] (MRP) (MRP-m-tc) y [la actitud que ellas tomaron, en especial a ese grupo, y parece que algo ayudó] (FMA), [pero yo no dejo que las cosas pasen así] (MRPs)(2)(mepa).

$(P)$ ¿En quién incide? $(\mathrm{R})$. [En mis hijos, porque ellos son unas personas que les doy amor y respeto por los demás, les he dado el valor de la autoestima, de que ellos son importantes, de que ellos valen, que nunca se dejen tratar mal. Entonces ellos se han creado y son personas que se expresan y no tienen miedo a expresar lo que ellos sienten] (MRPs)(2)(mepa)... [He influido bastante en mis hijos y bastante en mis estudiantes] (MRPs)(2)(mepa).

$(P)$ ¿De qué forma en los estudiantes? (R). [No solo en lo que les pueda enseñar] $(\mathrm{MRPs})(2)(\mathrm{mepa})$, [porque a veces uno aprende más de ellos, pero sí en el respeto, la tolerancia. Darles no solamente la oportunidad de lo que ellos son como estudiantes, sino de lo que ellos viven] (MRPs)(2)(mepa), [Porque uno a veces, sobre todo aquí, hay muchos muchachos con problemáticas diversas, sumercé lo ve...] (MRPs)(2)(mepa).

Como resultado de la revisión de las siete situaciones fue necesaria la reducción eidética en 24 formas que aparecen entre paréntesis dentro de las narrativas, ubicadas transversalmente y constituyen el tercer paso en los resultados. Son como sigue: se agrupan en tres categorías, en la categoría de situación con el tema de género, se trabajan siete (7) formas de reducción, a saber: (1) acto discursivo que se constituye dentro de relaciones sociales basadas en las diferencias percibidas entre los sexos (ADCRBDS); (2) acto subjetivo, o forma primaria de relaciones simbólicas de poder (ASFPRSP); (3) construcción discursiva en campos sociales de fuerza (CDCSF), (4) construcción de símbolos culturales en ocasiones contradictorios (SC); (5) conceptos normativos, resultado de la interpretación de los símbolos (CN), (6) acto subjetivo que se institucionaliza en las organizaciones sociales (familia, economía, política, educación) (lyO); y (7) identidad y subjetividad reproducidas a partir de la transformación de la sexualidad biológica en-generada y aculturada biográficamente en los actos de subjetividad de género (lyS).

La segunda categoría, escenario, desde los marcos de la experiencia, se seleccionan diez (10) formas de reducción, así: (1) marco de referencia es primario (MRP); (2) Modelo de referencia permite transponer claves y proporcionar elementos base para transformar la acción (MRP-m-tc); (3) marco de referencia se basa en un modelo de (hombre-mujer) (MRB-m-f); (4) marcos de referencia primarios naturales (MRPn); (5) marcos de referencia primarios sociales (MRPs); (6) formas atribuidas a fenómenos naturales (MRPn)(1)(fn); (7) formas surgidas, de principio a fin, dentro de los sucesos y acontecimientos sin dirección ni guía (MRPn)(2)(dsandg); (8) manipulación patente del mundo natural desde una agencia viva (MRPs)(1)(mpmn); (9) mundos especiales en donde puede participar el actor (MRPs)(2)(mepa); y (10) manipulación del mundo físico adoptando la identidad de un procedimiento instrumental (MRPs)(3)(mmfai).

Por último, la tercera categoría, agente-audiencia desde la fenomenología de la percepción, comprende siete (7) formas de reducción, son: (1) hacer signo con el cuerpo (HSC); (2) envolver sus partes (CE); (3) desplegar sus partes (CD); (4) Fondo movimiento concreto (FMC); (5), Fondo movimiento abstracto (FMA); (6) actos subjetivos reflexionados generan consciencia (ASRC); y (7) actos subjetivos no reflexionados (ASNR).

\section{Textos fenomenológico-hermenéuticos}

Se presentan siete textos en relación con las siete situaciones extraídas

La reescritura del texto fenomenológico-hermenéutico, constituye la aproximación primera a las formas, incluyendo dentro de ello, el cruce de experiencias subjetivas e intersubjetivas, hacen parte las puestas en escena de quienes participaron en las situaciones. El fin mostrar la experiencia y dar sentido pedagógico desde los cuestionamientos en los vacíos, tensiones y posibilidades. 


\section{Texto situación uno}

En esta situación se evidencia la manera como los símbolos culturales (SC) contradictorios se van construyendo por la formadora. Uno de estos, que corresponde a una situación de género, cuando narra "Mi papá es pensionado del magisterio, mamá; no trabaja...gerente de hogar", deja ver en su acto subjetivo la manera en que una actividad de trabajo es negada, porque se tiene entendido que aquello remunerado es trabajo y lo no remunerado no es trabajo, a pesar de serlo. A continuación, aparece otro ejemplo, corresponde a la segunda categoría, respecto a los hijos, cuando dice "el primero si fue de sorpresa, era muy joven... mi proyecto de vida era otro" (Entrevistada) Esta enunciación revela el enmarcado interpretativo que proviene de un Modelo de referencia primario natural (MRPn). Además, se percibe un acto subjetivo no reflexionado (ASNR), que corresponde a la categoría agente-audiente, en fenomenología de la percepción, que se explica cuando aduce la siguiente razón: "una falta de conocimiento, porque digo yo por ingenuidad" (Entrevistada) Esta razón deja ver cómo se pasan por alto mundos especiales donde lo pedagógico y educativo son claves, en donde, precisamente, puede participar el actor (MRPs)(2)(mepa). En esta situación el vacío está presente y suscita interrogantes que apuntan a la formación institucional, cabe aquí preguntarse, en el contexto educativo: ¿Se forma para la reflexión de nuestros actos subjetivos de género? ¿Se desarrollan procesos de enseñanza-aprendizaje a nivel universitario que permitan concienciar el manejo de nuestros cuerpos? Se infiere que las experiencias de los estudiantes no se toman en cuenta desde la formación docente, en particular, según la entrevistada, porque no se relaciona enseñanza y vivencias, descuidando la riqueza que el agenciamiento del cuerpo encierra (prevención de embarazo sorpresivo).

\section{Texto situación dos}

"No tuve la presencia de mi papá, sí... es algo fundamental en el desarrollo, la presencia del padre y de la madre. Pero no creo que me haya hecho mucha falta tampoco, porque mi mamá supo defenderse. Entonces, no teníamos todo lo material, pero sí teníamos mucho cariño, mucho afecto" (Entrevistada (s), 2014) Esta expresa una construcción de símbolos culturales contradictorios (SC), donde identidad y subjetividad (IyS) se van dando desde la construcción discursiva en campos de fuerza (CDCSF). Es decir, la formadora considera fundamental la presencia de padre y madre. Sin embargo, su niñez estuvo enmarcada por la ausencia de este, quien, con ese acto subjetivo-intersubjetivo con la mamá, va dejando vacíos de su acto subjetivo no reflexionado, agudizándose por tratarse de un agente educativo, como lo deja ver la formadora cuando en la situación (1), dice: "mi papá pensionado del magisterio" (Entrevistada) Esto nos lleva a preguntar: En general: ¿Existe consciencia del acto subjetivo de género en quienes educan? Y en particular: ¿Cuál es la consciencia de los actos subjetivos de género en quienes desarrollan procesos de enseñanza-aprendizaje en instituciones de formación docente?

De otra parte, también en esta situación dos se reitera una construcción discursiva en campos sociales de fuerza (CDCSF), categoría de situación de género, al comentar la formadora: “... ya en la adolescencia sí me sentí un poco más sola, mi mamá se fue con mi papá... quedamos casi que solos... mi papa le dijo a mi mamá: o ella o sus hijos... Y ella se fue. Quedamos casi que solos... quedamos casi que solos...y yo (yo) terminé ya el bachillerato. Al año siguiente quedé yo (yo) embarazada, me tocaba... no pude estudiar, mejor dicho... yo tenía otro proyecto de vida que era estudiar una ingeniería... era muy joven, acababa de salir del colegio, entonces mi proyecto de vida era otro, quedé embarazada..."(Entrevistada) En lo narrado se da un acontecimiento que interrumpe la normalidad de la historia de vida, por un hecho: queda embarazada, que corresponde a la manera como se hace signo con el cuerpo (HSC), prevaleciendo un acto subjetivo no reflexionado (ASNR). No existe un aprovechamiento desde la formación de mundos especiales donde puede participar el actor (MRPs)(2)(mepa), que permitan cuestionar el proceder en su acto, esto por la incertidumbre y los vacíos generados. Su connotación es significativa, porque desde allí pueden trabajarse las maneras de formar al ser humano para escudriñar las acciones desde donde se produjeron los hechos. Al hacerlo se hubiera involucrado a los actores escénicamente implicados papá (compañero)-mamá (formadora)-los dos responsables del embarazo; en quienes hubiera podido generarse un acto subjetivo reflexionado con consciencia. Se derivan de ello estos interrogantes: ¿Se ha contemplado enseñar la consciencia del acto de subjetividad de género desde las vivencias de nuestros estudiantes? o ¿Se pueden generar procesos de enseñanza-aprendizaje sobre el acto de subjetividad de género sin existir percepción en quién educa?

\section{Texto situación tres}

El texto por revelar muestra la manera como el concepto de género entra en evidencia en la narrativa de la formadora: "empezamos al tiempo a estudiar, él empezó a estudiar economía y yo entré a estudiar idiomas, a él no le gustó la economía y se retiró... yo sí seguí estudiando... Pero eso fue terrible porque a él no le 
gustó que yo siguiera, porque el sentía que yo iba más adelante que él y entonces... para estudiar eso fue terrible, yo le soy sincera... eso fue terrible" (Entrevistada)

Al revisar se encuentra la forma en que a través del acto subjetivo se intersubjetiva una (CDCSF), esto porque se presenta la interpretación basada en una forma primaria de relaciones simbólicas de poder (ASFPRSP) y (ADCRBDS). La situación encontrada evidencia un vacío frente al reconocimiento, la diferencia y la manera de negociar mundos donde quepan las dos posibilidades; esto tiene que ver con (MRP-m-tc) y donde las agencias educativas a nivel formativo están llamadas a movilizarse. Se interroga por eso ¿Los profesionales en ciencias sociales, ética y comunicación han contemplado contenidos donde se dinamice desde las vivencias de los estudiantes el reconocimiento de la unicidad, del otro/a, la negociación y el dialogo en tanto posibilidad pedagógica de reflexión?

\section{Texto situación cuatro}

Se escenifica la manera cómo dos actores, formadora y esposo, se encuentran involucrados dentro de una situación de género. Se observa aquí, por un lado, la agencia de ella en su acto, cuando dice lo siguiente: "mi trabajo pueda que no sea al aire libre, como le toca a usted, pero me tocan muchas cosas... Me toca llegar a una casa y responder por otras actividades... los hijos y todo. Yo creo que es más trabajo el que uno hace" (Entrevista, Entrevistada); mientras que, por el otro lado, él escucha como audiencia. Al movilizar las experiencias, se intercambian los papeles, cuando ella pasa a ser audiencia y escucha a su esposo, cuando recuerda sus palabras: "mi esposo me dice, a mí me toca duro... ir a una obra...y usted simplemente llega a una oficina a sentarse" (Entrevistada) En esta situación se ejemplifica una interacción simbólica, que evidencia aquí la intersubjetividad dinamizada entre las dos subjetividades. En cualquiera de las vivencias cada uno de los actores reclama un reconocimiento. Sin embargo, el fenómeno de inequidad de género es un patrón cultural (modelo estereotipado de hombre) que se reitera y afianza al institucionalizarse, en este caso, solo una de las dos subjetividades dinamizadas intersubjetivamente se reconoce: la del esposo. A pesar de que ella intenta dar una explicación (justificación), se percibe en su discurso algo de resignación de un sujeto débil o atemperado, que por ser un acto subjetivo no reflexionado (ASNR), categoría de agente-audiencia desde la fenomenología de la percepción -, afianza un modelo fabricado o estereotipo de hombre, visible en la formadora cuando narra: "yo creo que es más trabajo el que uno hace, pero ellos no lo ven así, ellos llegan a la casa, se sientan, de vez en cuando que le colaboran a uno, pero de resto" (Entrevistada).

Esta situación se reafirma aún más en las situaciones 5 y 6, en donde llama la atención, cómo el proceso de intersubjetividad toma forma desde la construcción discursiva de campos de fuerza (CDCSF), correspondiente a la categoría de situación leída desde el género. Aquí tiene que ver la identidad y subjetividad (lyS) y la manera como esta resulta institucionalizada (lyO), en este caso, en la familia. Este ejemplo muestra cómo lo institucional no es resultado de un consenso, sino el producto de un conflicto, el cual continúa por la falta de reconocimiento de una de las subjetividades implicadas allí. Estamos aquí frente a las tensiones y vacíos que están por revisarse desde las situaciones mismas. Cabe preguntar aquí: ¿Se enseña a partir de la vivencia de nuestros estudiantes el proceso mediante el cual un acto subjetivo, al intersubjetivarse, construye símbolos que se convierten en normas, que finalmente se institucionalizan, que no siempre son producto del consenso, sino de las tensiones y vacíos que reclaman reconocimiento y equidad? ¿Se puede educar y reflexionar pedagógicamente sin tener consciencia del acto de subjetividad de género?

\section{Texto situación cinco}

La construcción discursiva en campos de fuerza (CDCSF), presente en la intersubjetividad dentro de la cual transita la experiencia de la formadora, se pone en escena frente a los agentes con quienes intercambia experiencias, en este caso el esposo. Ello se destaca cuando la formadora manifiesta: "no tengo tiempo de sentarme a descansar cinco minutos" (Entrevistada), se encuentra en su acto subjetivo un referente de interpretación basado en una manipulación del mundo físico (MRPs)(3)(mmfai), es decir, se observa cómo el cuerpo se instrumentaliza volviéndose objeto manipulable frente a la demanda del modelo fabricado de hombre esposo. En ella se evidencia cómo se va en-generando una identidad y subjetividad instrumental (lyS). Esto se ratifica cuando dice: "a mí me toca duro, al comienzo él llegaba y yo estaba trabajando y él tiene de 12:00 a 1:15 de almuerzo, y a la 1:30 empieza a trabajar. Entonces yo llegaba a la casa y él pretendía que cuando yo llegará le tuviera servido todo, entonces eran unas peleas porque no alcanzaba a comer" (Entrevistada) además de encontrarse (CDCSF), se hace signo con el cuerpo (HSC) cuando ella responde con el acto esperado por su esposo. En este modelo de fabricación (MRPs-m-f) intervienen la construcción simbólica contradictoria de estereotipos de mujer (CS), que se constituyen en normas (CN) y se institucionalizan en la organización familiar (lyO). Este hace parte de la categoría de situación de género, que culmina con un cuerpo que se envuelve (CE) y termina discursivamente, cuando la formadora enuncia 
un mundo que no es el suyo. A partir de esta situación surge un cuestionamiento: ¿Dentro de lo educativo se han desarrollado prácticas pedagógicas de reflexión frente al significado del cuerpo y la manera de hacer signo desde los actos mismos donde nos involucramos en la dinámica cotidiana de la vida?

\section{Texto situación seis}

Se percibe en la experiencia un cruce de intersubjetividades entre los dos actores. En cada una de ellas se manifiesta la percepción de mundos donde la construcción de símbolos (CS) y construcción de normas (CN) dejan ver la identidad y subjetividad (IyS) de los actores implicados. En este caso prevalece la forma de ella al hacer signo con su cuerpo (HSC), un cuerpo que se encoge (CE) para dar respuesta al modelo de fabricación del esposo (MRPs-m-f); su cuerpo físico resulta manipulado por la identidad y subjetividad (lyS) institucionalizada en la familia (MRPs)(3)(mmfai). La formadora, al hacer signo con su cuerpo, toma de fondo el movimiento concreto (FMC), expresa la imposición del mundo que representa la subjetividad de su esposo, al evocar ese mundo en donde, aunque construido entre ella y él, prima el de él. Este cruce de subjetividades e intersubjetividades no negociadas, ni dialogadas, se traducen así: "yo por no pelear, no digo nada, yo asumo todo" (Entrevistada) Se llama la atención del acto subjetivo de género, por ser una manipulación en la cual el esposo, agente, hace signo con su cuerpo, mediante la pelea que le sirve para ostentar y afianzar su modelo de poder y fuerza, modelo fabricado (MRPs-m-f). El resultado: la agente encoge su cuerpo (CE), a pesar de que manifiesta su inconformismo, pronuncia o evoca un mundo que no es el deseado. En este cruce de intersubjetividades caben estos cuestionamientos: ¿Quienes están aprendiendo contenidos de asignaturas de ciencias sociales y de derecho (Zuñiga, 2006) han reflexionado frente al trabajo doméstico realizado por las mujeres sin remuneración? ¿Es solo parte del derecho los escenarios públicos? y ¿Qué o cuáles aspectos han impedido trabajar escenarios privados donde la inequidad hace presencia? ¿Cuáles son los límites pedagógicos de reflexión, las personas o los contenidos? ¿Cuáles son los contenidos de las asignaturas impartidas a nivel universitario, y en esta dinámica, caben narrativas o historias de vida como apuesta por el sentido y tacto pedagógico para leer lo privado e incluirlo dentro de un lenguaje comunicativo y desde allí trabajar posiciones críticas?

\section{Texto situación siete}

Al narrar "Yo me he sentido bien" y decir:

"... por ejemplo, sí me dio duro, cuando empecé a trabajar; entonces la gente se aprovecha mucho de uno, incluso, cuando yo estaba trabajando por contrato. Cuando yo era joven trabajé en la Alcaldía por OPS. Entonces una vez hubo cambio, era por política, de alcalde. Entonces la directora me dijo tiene que hablar entonces con el Secretario de Educación, y va y habla con él para que por favor le colabore. Va y le dice, oiga, que usted ha trabajado. Fue en el 93, cuando salió la Ley 60 , y yo fui hablé con el viejo este y me propuso una cosa que usted ni se imagina: entonces lo que yo hice, le menté hasta la abuela y entonces me quedé sin trabajo, pero yo: dije preferible sin trabajo, no me gustó, me sentí tan ¡uyyyy! Muchas compañeras salieron hasta nombradas pero yo no..." (Entrevistada)

Asistimos a un acto de subjetividad de género enlazando un nudo de subjetividades: la de la formadora solicitando empleo, la de la directora vinculando a quien solicita y la subjetividad de quien concede esta posibilidad. Ella establece un contacto con el Secretario de Educación, quien deja ver en el acto de subjetividad de género, una "propuesta de una cosa inimaginable" (Entrevista, Entrevistada), según manifiesta la formadora. En este nudo de subjetividades e intersubjetividades estamos frente a un claro fenómeno de inequidad de género. Las tensiones se evidencian porque, por un lado, está la subjetividad de la docente desde su profesión, solicitando se le permita ejercer su papel en el campo dentro del cual fue formada, y por el otro, la subjetividad de un representante de políticas educativas, nombrando a quienes constituirán la planta de personal por generar este servicio educativo. Se patentiza en él un acto de subjetividad de género alejado de la reflexión y la consciencia del mismo; sin embargo, su poder permite la institucionalización del acto. En este caso no da empleo a quienes no entran en el juego de su modelo primario social de representación fabricado (estereotipo de hombre y de su percepción de lo que simboliza para él la mujer) (MPRS-m-f); en tanto que sí lo concede a quienes entran en este juego.

La aceptación se ve cuando la formadora se refiere a quienes respondieron simbólicamente con su cuerpo (HSC), constituyéndose en un acto subjetivo no reflexionado (ASNR): "muchas compañeras salieron hasta nombradas" (Entrevistada) Un ejemplo más de cómo se construyen de manera contradictoria símbolos culturales (CS), en este caso, la reproducción de la inqeuidad de género. La situación descrita suscita otros interrogantes al respecto: ¿Cuál es la naturaleza del acto subjetivo de género del Secretario de Educación? ¿Es consciente del radio de acción de su acto subjetivo y del tipo de agencia implicado dentro de la institucionalidad educativa dependiente de su actuar? ¿Qué tipo de políticas de género caben en este tipo de actuaciones? 
Otra forma de institucionalizar actos de subjetividad de género lo constituye la siguiente narrativa:

"Por ejemplo en La Presentación si vi cuando yo trabajé... más apoyo a los hombres... en el trato, pese a que conmigo bien, pero se veía cómo a los hombres los consentían. Si tenían que pedirle permiso se los daban sin decir nada, pero uno llegaba a pedir permiso ahí sí grave, pero con ellos sí eran condescendientes" (Entrevistada), una construcción simbólica (CS) (CN). "Por ejemplo en La Presentación una vez hubo un problema con unos profesores y profesoras que se metieron, y unas eran casadas y, ¿qué hicieron? Sacaron a todas las mujeres, que por vagabundas, y las echaron del Colegio. A los hombres sí los dejaron seguir trabajando (ADCRBDS). Entonces uno sí sentía esa falta de equidad. A los hombres no les dijeron nada y a las mujeres sí las echaron" (Entrevistada).

Vemos otro ejemplo de construcción simbólica cultural (CS) y contradictoria: la directora hace signo con el cuerpo (HSC) al sancionar docentes, basada en modelo de mujer y hombre sin reflexión. Se está aquí en presencia de a un acto subjetivo no reflexionado (ASNR) acerca del cual debemos preguntarnos: ¿Ser directivo es garantía de un proceder justo, equitativo y con conciencia de género? ¿Se puede garantizar un trabajo de equidad de género cuando las políticas son diseñadas sin consciencia de género? ¿Se tendrá oportunidad de trabajar vivencias de los estudiantes para dar sentido y tacto pedagógico a su actuar, si quien educa no percibe la riqueza de la reflexión?

En esta situación se vislumbran mundos posibles (MRPs)(2)(mepa), donde lo pedagógico y educativo pueden hacer presencia. Lo revela la expresión de la formadora cuando se le pregunta en quiénes incide y en su respuesta menciona "en los estudiantes, no solo en lo que les pueda enseñar" (Entrevistada) De alguna manera este "no solo en lo que les pueda enseñar" resulta ser una contradicción que se reitera cuando dice "no solo la oportunidad de lo que ellos son como estudiantes, sino lo que ellos viven, porque uno a veces, sobre todo aquí, hay muchos muchachos con problemáticas diversas" (Entrevistada) La formadora percibe las problemáticas pero no alcanza a percibir el tacto pedagógico latente aquí. Se acerca potencialmente (MRPs)(2)(mepa) a dejar abierta la posibilidad de actuar pedagógicamente en esos vacíos percibidos en las problemáticas de sus estudiantes, donde pueden trabajarse claves y transposición de claves que les permitan a estos comprenderse y comprender el mundo dentro del cual están inmersos. Valdría preguntar entonces: ¿Se puede enseñar desde la vivencia contenidos relacionados con el área de orientación de quién forma? ¿Se puede proyectar enseñanza sin tener consciencia de lo representativo de un acto donde la experiencia constituya sentido y significado?

\section{DISCUSIÓN}

La experiencia analizada ofrece evidencias reveladoras de un proceso de interacción simbólica, donde el acto de subjetividad de género, narrado por la formadora ilustra el análisis de las tres categorías: la situación (de género), el área de acción o escenario (marcos de la experiencia) y el agente-audiente (fenomenología de la percepción), soportes teóricos y metodológicos de la reflexión. Examinar la subjetividad escénica permitió ver como la dinámica intersubjetiva involucra a los distintos actores, mediante actos y discursos que, puestos en perspectiva, y desde una lectura parcial (experiencia particular) de una formadora universitaria, destacan los roles de cada uno de los actores, así:

El padre de la formadora, quien con sus actos y discursos replica y refuerza situaciones de inequidad de género, es un agente educativo inconsciente del acto reproductor de estereotipos: pero sí manipula y replica símbolos contradictorios de hombre y mujer; evidenciando no solo una ausencia de reflexión sobre sus actos, sino, además, una falta de sujeción-agencia (Haraway, 1991; Butler, 2007) de su proceder, que responde a modelos primarios fabricados de poder (Foucault, 1989) - machismo. Por otra parte, la directora del colegio, quien desde el cargo sanciona docentes, toma como fundamento marcos de referencia primarios basados en modelos de hombre y mujer tradicionales, modelos fabricados de poder y machismo. Su poder como funcionaria le permite aplicar una norma sancionatoria, destituyendo a las docentes. En ello se da una ratificación y refuerzo de la institucionalidad de la norma amparada en su cargo administrativo. Tampoco, aquí existe una consciencia reflexiva del acto subjetivo de género, se observa sí una cadena de réplica de símbolos contradictorios de inequidad de género.

De otro lado, aparece en escena el Secretario de Educación, quien a través de su discurso y acto deja ver un modelo fabricado que se institucionaliza desde su percepción de construcción de símbolos contradictorios de lo que representa para él la mujer, materializado y reforzado en el nombramiento de docentes. Su poder político reproduce un eslabón más de la cadena de inequidad que él ayuda a institucionalizar. Sus actos revelan una falta de consciencia de su actuar. Finalmente, la narradora formadora, quien si bien vislumbra situaciones de inequidad, y reconoce su sentido pedagógico en otros campos distintos del saber, no establece el cabal vínculo entre lo que constituye su experiencia y la riqueza que podría dinamizar como practica transformadora en el campo formativo universitario. Así, aunque alcanza a tener una postura crítica, esta no alcanza para emanciparse de los estereotipos, modelos, normas 
de otras subjetividades. El poder de dominación de estos referentes se impone; frente a ello, la formadora concede espacio para que se impongan las subjetividades que las replican. Aquí su cuerpo hace signo al resignarse a contemplar mundos de otras subjetividades, que incluso la podrían llevar a transgredir radicalmente dichas situaciones, a cambio, su subjetividad se debilita y opaca. Así su potencial de acción, en especial, en cuanto al tacto pedagógico queda por realizarse.

En lo fundamental, se pude afirmar que el análisis de la interacción simbólica de subjetividades de género, permite cuestionar el papel de quienes forman en contextos educativos universitarios (Jiménez et al., 2013). La reproducción de estereotipos, modelos, discursos, comportamientos institucionalizados por los propios actores evidencia, en general, el vacío de consciencia frente al acto de subjetividad de inequidad de género. Se imponen así, a veces involuntariamente, los actos subjetivos refrendadores del poder administrativo, político, educativo, social, económico, masculino predominantes. Así mismo, no puede desconocerse que este acto toma forma en la cotidianidad desde donde se está haciendo historia en y a través de nuestras biografías. El cruce de subjetividades e intersubjetividades (Santibáñez, 2003) retroalimenta esta situación llena de tensiones y vacíos. La ausencia de consciencia de la riqueza que encierra la relación experiencia vivencial y consciencia de cada uno de los actos, desde la formación docente, ponen en entredicho la agencia adecuada de una formación para la emancipación, esto es, una actitud crítica frente a todo aquello que refleje inequidad, injusticia, y por tanto abuso. Una formación autónoma, responsable y libertaria queda pendiente de su verdadera realización.

El análisis desde la experiencia y el simbolismo que encierra el acto de subjetividad de género permite conocer e interpretar la manera como los agentes educativos permanecen atrapados en su accionar en experiencias constantes y cotidianas de inequidad de género. En este sentido, resulta ilustrativa la referencia histórico-biográfica de la formadora, puesto que a través de ese referente se puede reconocer como transitan tanto las subjetividades como las intersubjetividades, institucionalizando la inequidad de género, muy a pesar de las tensiones, vacíos y posibilidades presentes en el cruce de subjetividades que, a pesar de entrar en disputa por su reconocimiento, dejan en el camino una subjetividad reconocida y otra sin reconocer. Los vacíos en este sentido afectan a unos y otros. Incluso, se dan situaciones en las cuales a quienes no se les reconoce su subjetividad, pese a la dureza de la experiencia, no alcanzan a considerar nuevos mundos deseados que se opongan a los modelos fabricados (estereotipos). Como sucede con la formadora: se oscila entre actos de resignación o de subversión, esta última reflejada, por ejemplo en una renuncia que pese a su tensión, tampoco alcanza a generar cambios sustanciales. Se plantean aquí estos cuestionamientos: ¿Dónde, cuándo y cómo se genera tacto y sentido pedagógico en quienes están involucrados en procesos educativos y formativos a nivel universitario? ¿Se desconoce y se evade el requerimiento de que para educar debemos ser formados (Gadamer, 2007)?

La persistencia de estos actos de subjetividad de género en la cotidianidad, hace pensar en lo necesario de la lectura, comprensión y escritura críticas como método de reflexión y concientización, desde donde puede accederse tanto a la dimensión empírica como a la dimensión lógica del conocimiento como acto constructivo. Se debe reiterar aquí que a partir de su interiorización y aplicación no se pretende la resolución de problemas, sino la apertura de interrogantes frente al significado y sentido de la experiencia, y asimismo, se busca dar relevancia a la posibilidad de hallar allí el vínculo con el sentido y tacto pedagógico, puestos al servicio del ejercicio docente y pedagógico en la educación superior. Se espera responder a los reclamos de conocimiento y acción frente a la unicidad de las experiencias de quienes son educados (Sepúlveda, 2004), para fortalecer su subjetividad (individualidad) en la pluralidad y diversidad (sociabilidad-colectividadintersubjetividad), esto es, formar y formarse (Gadamer, 2007) como sujetos activos de participación y cambio de las situaciones aquí analizadas.

Es posible que esta mirada atente contra una subjetividad que no merece una implacable disección fenomenológica-hermenéutica. Sin embargo, no se puede olvidar que en la opacidad y en los vacíos de ese agente formador cuestionado es donde caben posibilidades emancipadoras de sentido y tacto pedagógico, porque es desde allí desde donde pueden trabajarse "modelos para" (Goffman, 2006) encontrar las claves y llegar a transponerlas a partir de esas vivencias que merecen conocerse. Se comprende así que ciertos signos emancipadores, que no trascienden de lo meramente individual, pueden, a través de una reflexión y concienciación construida desde la propia experiencia, reavivarse y potenciarse en cambios significativos, esto es, por ejemplo, que al reconocerse como sujeto activo se pronuncie (Santibáñez, 2003; Zuñiga, 2006), y al pronunciarse reconozca a sus estudiantes de igual forma. Este reconocimiento podría vislumbrar la unicidad en los estudiantes (Alvarinas, 2011) quienes necesitan se les trabaje procesos de enseñanzaaprendizaje donde cada uno se reconozca, y a su vez, reconozca al otro/a en la socialización, constituyéndose en este sentido, una apuesta por la equidad de género dentro de la diferencia. 


\section{CONCLUSIONES}

De lo analizado y discutido en este trabajo se pueden obtener las cuatro siguientes conclusiones principales:

i) El análisis desde la experiencia y el simbolismo que encierra el acto de subjetividad de género permite conocer e interpretar la manera como los agentes educativos permanecen atrapados en su accionar en experiencias constantes y cotidianas de inequidad de género.

ii) Percibir la persistencia de estos actos de subjetividad de género en la cotidianidad, hace pensar en lo necesario de la lectura, comprensión y escritura como método de reflexión y concientización.

iii) Es ilustrativa la referencia histórico-biográfica de la formadora, puesto que a través de ese referente se puede reconocer cómo transitan tanto las subjetividades como las intersubjetividades, institucionalizando la inequidad de género.

iv) Al analizar la interacción simbólica del acto subjetivo de género, es posible reconocer vacíos, tensiones y posibilidades desde la mirada parcial, para una vez concienciados, cuestionarlos desde los contextos educativos universitarios, en procura de equidad de género.

\section{AGRADECIMIENTOS}

Esta investigación estuvo apoyada por la Asociación Universitaria Iberoamericana de postgrados (AUIP), quien proporcionó la beca de pasantía internacional.

\section{REFERENCIAS}

Alonso L.E., Sujeto y discurso: El lugar de la entrevista abierta en las prácticas de la sociología cualitativa. En, Métodos y técnicas cualitativas de investigación en Ciencias Sociales. Delgado J. M y Gutiérrez J (Ed.) 225-240. Editorial Síntesis. Madrid. (1999).

Alvarinas, M. y Fernández. M., Percepciones de futuros maestros ante nuevos contextos de aprendizaje. Form. Univ. 4(4). 37-46. (2011).

Butler, J., El género en disputa. El feminismo y la subversión de la identidad. Ediciones Paidós lbérica, S.A. Barcelona. 263-275 (2007).

Carabajo, R. A., La metodología fenomenológico-hermenéutica de M. Van Manen en el campo de la investigación educativa, posibilidades y primeras experiencias. Revista de investigación educativa. 26 (29) 409-430. (2008). http://revistas.um.es/rie/article/viewFile/94001/90621. Acceso, 6 de febrero (2013)

Díaz de V., J.M. La prohibición de una discriminación arbitraria entre privados. Revista de Derecho de la Pontificia Universidad Católica de Valparaíso. 42. 149-186. (2014).

Díaz L.M. P., La mujer, expresión de humanidad. Una propuesta de identidad en el pensamiento de Edith Stein. Teología y Vida. 45(1). 85-91 (2004).

Freire P., Pedagogía del oprimido, 2da.edición. Siglo XXI editores. México. (2005).

Foucault, M., Historia de la sexualidad. Siglo XXI. México. 1. 118-119 (1989)

Gadamer H.G., Verdad y Método. Decimosegunda Edición. Ediciones sígueme. España. 38-55 (2007).

Goffman, E., Los marcos de la experiencia. Primera edición. 227. 11-43. Colección monografías. Centro de Investigaciones Sociológicas .Madrid. (2006).

Haraway, D.J., A Cyborg Manifesto: Science, Technology, and Socialist-Feminism in the Late Twentieth Century. Simians, Cyborgs and Women: The Reinvention of Nature. 149-181. Routledge, New York (1991).

Hurtado, M., Productividad de la mirada como performance. Cátedra de artes. ISSN 0718-2759 (en línea), 3. 59-80. (2006) http://catedradeartes.uc.cl/pdf/04productividadfromCatedra3-7.pdf. Acceso: 10 de febrero (2015) 
Ibáñez J., (Ed.) Nuevos avances en la investigación social. La investigación social de segundo orden. Primera edición. 22. Suplementos Anthropos. Barcelona. (1990).

Jiménez, M. Reveco, J., González, M. Astudillo, C. Dilemas Ideológicos ante una Formación Universitaria con Sello Valórico Distintivo: El Caso de una Carrera de Ingeniería. Formación Universitaria. 6(4) 13-26 (2013)

Lobato, C. y Madinabeitia, A., Perfiles motivacionales del profesorado ante la formación en metodologías activas en la universidad. Form. Univ. 4 (1) 37-48. (2011).

López, A.M., ¿Son el condicional y la disyunción realmente comparables? Universum. 28(2). 229-242 (2013).

Mancilla, T. S., Interpretación y fe: una breve presentación de la hermenéutica teológica de Paul Ricoeur. Teología y Vida. 47(4). 531-539 (2006)

Martínez, Y., Hermenéutica de las representaciones icónicas. Revista. Investigium Ire. 4(1). 197-215 (2013). http://investigiumire.iucesmag.edu.co/ire/index.php/ire/article/view/54/53.PDF.Acceso: 4 de enero (2015).

McKernan, J., Investigación-acción y curriculum. Primera edición. 21-54. Ediciones Morata. S.L. Madrid. (1999).

Mena M.P., Consentir y narrar la vida. Veritas, 30. 29-43. (2014)

Merleau-Ponty, M., Fenomenología de la percepción. 15-21. Editorial Planeta. De-Agostini. S.A. Barcelona. (1993).

Póo, A.M. y Vizcarra, M. B., Diseño, implementación y evaluación de un programa de prevención de la violencia en el noviazgo. Ter psicol. 29(2). 213-223. (2011).

Santibáñez. E., Psicolingüística de la interacción educativa. El uso del lenguaje en el aula. Primera edición. 53-58. Edición Santibáñez. Navarra-España. (2003).

Saúl. A. M., (Coordinadora) y otros veintisiete autores, Paulo Freire y la formación de educadores: múltiples miradas - Primera edición. 106-158. Sao Paulo: Siglo XXI Editores. (2009).

Scott, W. J., Género e historia. Primera Edición. 66-94. Serie Clásicos y vanguardistas en estudios de Género. Fondo de cultura económica. México. (2008).

Sepúlveda, V. L., Volver a intentarlo: proyecto educativo-laboral de jóvenes adultos sociales. Última década. 12(21). 51-79. (2004).

Thezá M.M., Apuntes para una Resignificación de la Participación Política de los Jóvenes a partir del Eje Igualdad-Desigualdad. Última década. 11(19). 47-70. (2003).

Van Manen, M., El tacto en la enseñanza: el significado de la sensibilidad pedagógica. 1ra. Edición. 96135 Paidós Ibérica. Barcelona (1998).

Van Manen, M., Investigación educativa y experiencia vivida. Ciencia Humana para una pedagogía de la acción y la sensibilidad. Editor. S.A. Idea Books .Barcelona. 20-26. (2003)

Zúñiga, A.Y, El derecho como representación-deformación. Un análisis de su construcción adversarial en clave de género y derechos fundamentales. Rev. Derecho (Valdivia). 19(1). 33-59. (2006). 